Journal Club

Editor's Note: These short reviews of a recent paper in the Journal, written exclusively by graduate students or postdoctoral fellows, are intended to mimic the journal clubs that exist in your own departments or institutions. For more information on the format and purpose of the Journal Club, please see http://www.jneurosci.org/misc/ifa_features.shtml.

\title{
Warming up the Cold Reception at a TRPM8 Function
}

\author{
Wendy Y. W. Cheung, Noo-Rie Ha, Michael W. H. Suen, Chen L. Xu, and Cheng Wei T. Yang \\ Department of Cellular and Physiological Sciences, Life Sciences Centre, University of British Columbia, Vancouver, British Columbia, Canada V6T 1Z3 \\ Review of Andersson et al. (http://www.jneurosci.org/cgi/content/full/27/12/3347)
}

The transient receptor potential (TRP) family of cation-permeable channels responds to mechanical, thermal, and chemical stimuli originating from inside and outside the cell (Clapham, 2003). The TRP (melastatin)-8 (TRPM8) channel is expressed in a subpopulation of temperaturesensing dorsal root ganglion (DRG) neurons and facilitates calcium influx at temperatures $<25^{\circ} \mathrm{C}$ (Peier et al., 2002). TRPM8 is also expressed in sensory nerves in deep tissues that encounter little temperature variation, suggesting that TRPM8 is also regulated by a temperatureindependent mechanism, perhaps through an endogenous agonist. Vanden Abeele et al. (2006) demonstrated that lysophospholipids (LPLs), which are produced by phospholipase $\mathrm{A}_{2}\left(\mathrm{PLA}_{2}\right)$, are able to prolong the open time of TRPM8 channels and that downregulation of $\mathrm{PLA}_{2}$ inhibits channel activity and TRPM8-mediated responses. In their recent publication in The Journal of Neuroscience, Andersson et al. (2007) further investigated the role of $\mathrm{PLA}_{2}$ and its products on TRPM8 channel activity.

The authors applied $\mathrm{PLA}_{2}$ inhibitors to Chinese hamster ovary $(\mathrm{CHO})$ cells over-

Received May 23, 2007; revised June 5, 2007; accepted June 5, 2007.

We thank Stephen R. Bond (Department of Cellular and Physiological Sciences, University of British Columbia, Vancouver, British Columbia, Canada) for the valuable discussions and his generous support.

Correspondence should be addressed to Wendy Y. W. Cheung, Room 3340, Life Sciences Centre, 2350 Health Sciences Mall, University of British Columbia, Vancouver, British Columbia, Canada, V6T 1Z3. E-mail: wendyyw@interchange.ubc.ca.

DOI:10.1523/JNEUROSCI.2353-07.2007

Copyright $\odot$ 2007 Society for Neuroscience $\quad$ 0270-6474/07/277617-02\$15.00/0 expressing TRPM8 to monitor increases in intracellular calcium evoked by cold or the chemical agonists icilin and menthol (Fig. 1). The nonselective $\mathrm{PLA}_{2}$ inhibitor $N$-(pamylcinnamoyl)anthranilic acid (ACA) abolished the responses to cold and icilin and decreased the response to menthol [Andersson et al. (2007), their Fig. 1 (http:// www.jneurosci.org/cgi/content/full/27/12/ 3347/F1)], and E-6-(bromomethylene)tetrahydro-3-(1-naphthalenyl)-2 $\mathrm{H}$-pyran2-one (BEL), a selective inhibitor of the calcium-insensitive $\mathrm{PLA}_{2} \quad\left(\mathrm{PLA}_{2}\right)$, produced similar results. However, the selective inhibitor of the cytosolic PLA $2\left(\mathrm{CPLA}_{2}\right), \mathrm{cPI}$ $[N$-\{(2S,4R)-4-(biphenyl-2-ylmethyl-isobutyl-amino)-1-[2-(2,4-difluorobenzoyl)-benzoyl]-pyrrolidin-2-ylmethyl\}-3-[4-(2,4-dioxothiazolidin-5-ylidenemethyl)-phenyl] acrylamide $\mathrm{HCl}$ ], had no obvious effect on $\left[\mathrm{Ca}^{2+}\right]_{\mathrm{i}}$ responses [Andersson et al. (2007), their Table 1 (http://www.jneurosci.org/cgi/ content/full/27/12/3347/T1)]. These findings suggest that the activation of TRPM8 is not regulated by all $\mathrm{PLA}_{2}$ proteins but is specifically controlled by the $\mathrm{PLA}_{2}$ subset.

Andersson et al. (2007) also examined the effects of $\mathrm{PLA}_{2}$ inhibition on native TRPM8 in cultured DRG neurons. The cultures were heterogeneous, with $\sim 11-$ $12 \%$ of the cells responding to cold stimulation, $\sim 7 \%$ to menthol, and $\sim 9 \%$ to icilin. Cold-sensitive neurons can be divided into two subpopulations: menthol sensitive and menthol insensitive. The menthol-insensitive population has a lower temperature threshold and does not express TRPM8 (Babes et al., 2004). In agreement with the experiments in $\mathrm{CHO}$ cells, treatment with ACA or BEL reduced the number of neurons that responded to cold or menthol and nearly abolished response to icilin [Andersson et al. (2007), their Table 2 (http://www.jneurosci.org/ cgi/content/full/27/12/3347/T2)]. The similarity in the proportions of coldsensitive, menthol-insensitive neurons in normal DRG cultures and cold-sensitive neurons remaining after inhibition of $\mathrm{PLA}_{2}(\sim 4 \%)$ is consistent with TRMP8 expression only in the menthol-sensitive subpopulation regulated by $\mathrm{PLA}_{2}$.

iPLA $_{2}$ breaks glycerophospholipids into polyunsaturated fatty acids (PUFAs) and LPLs; thus, the authors examined the effects of these compounds on TRPM8. The authors treated TRPM8-expressing CHO cells with LPLs of different head groups and acyl chain lengths and measured $\left[\mathrm{Ca}^{2+}\right]_{\mathrm{i}}$ responses and singlechannel activity. Zwitterionic lysophosphatidylcholine (LPC), and anionic lysophosphatidylinositol and lysophosphatidylserine all produced robust $\left[\mathrm{Ca}^{2+}\right]_{\mathrm{i}}$ responses, whereas a sphingolipid, sphingosyl-phosphorylcholine, had a modest effect [Andersson et al. (2007), their Fig. 5 (http://www.jneurosci.org/ cgi/content/full/27/12/3347/F5)]. LPC produced single-channel current activities comparable with menthol, albeit after a longer delay [Andersson et al. (2007), their Fig. 6 (http://www.jneurosci.org/ cgi/content/full/27/12/3347/F6)]. This latency suggests that LPC acts intracellularly, requiring time to translocate to the 
cytoplasm. Like menthol, LPC appeared to potentiate the effect of cooling in a dose-dependent manner, as shown by increases in current amplitude, $\left[\mathrm{Ca}^{2+}\right]_{\mathrm{i}}$ response, and temperature activation threshold [Andersson et al. (2007), their Fig. 7 (http://www.jneurosci.org/ cgi/content/full/27/12/3347/F7)]. The authors clearly showed that LPLs, rather than iPLA2 itself, were responsible for these responses, because ACA had no effect when applied in conjunction with LPL. The LPL response was dependent on TRMP8 because extracellular calcium was required, and application of these lipids was ineffective on untransfected cells.

PUFAs are the other product of glycerophospholipid cleavage by $\mathrm{PLA}_{2}$ activity and are known to activate a number of TRP channels. Therefore, it was expected that these compounds would mimic the effect of LPLs on TRMP8 activity. However, treatment with arachidonic acid, eicosapentaenoic acid, or docosahexaenoic acid nearly abolished $\left[\mathrm{Ca}^{2+}\right]_{\mathrm{i}}$ response to icilin and cold stimulation in CHO cells and reduced the response to menthol [Andersson et al. (2007), their Figs. 3 (http://www.jneurosci.org/cgi/content/ full/27/12/3347/F3), 4 (http://www.jneurosci. org/cgi/content/full/27/12/3347/F4)]. The authors showed that equimolar concentrations of PUFA and LPL (as would be generated by the cleavage of glycerophospholipids) had a net activation effect on TRMP8, but they suggested that cellular concentrations of PUFAs might be varied to regulate TRPM8 activity.

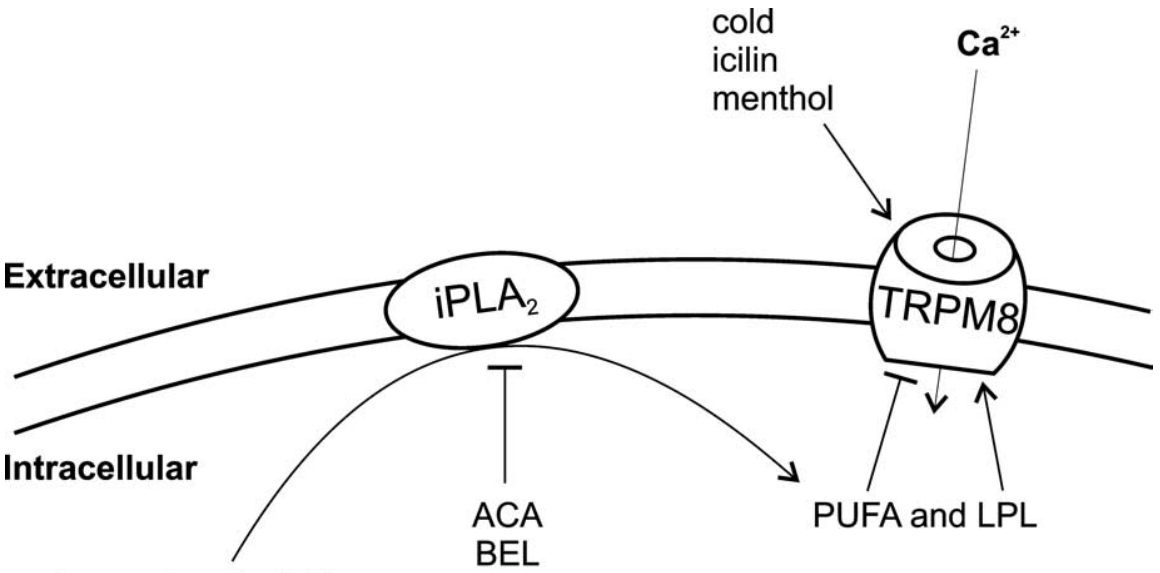

glycerophospholipid

Figure 1. Overview of TRPM8 regulation, as proposed by Andersson et al. (2007). TRPM8 channels are activated by cold and chemical agonists, like icilin and menthol, producing an influx of $\mathrm{Ca}^{2+}$. These channels are also modulated by endogenous lipid agonists derived from glycerophospholipids via iPLA $A_{2}$. PUFAs act as negative modulators, whereas $L P L s$ act as positive modulators. At equimolar concentrations of LPLS and PUFAs, there is net activation of TRPM8 channels, so inhibitors of iPLA 2 such as ACA and BEL reduce TRPM8 activity.

Andersson et al. (2007) have demonstrated that the endogenous products of $\mathrm{iPLA}_{2}$ are essential for regulation of TRPM8 (Fig. 1), which may explain why these thermosensitive ion channels are present in sensory nerves that rarely experience temperatures $<25^{\circ} \mathrm{C}$. However, the mechanism by which PUFAs and LPLs act to regulate TRPM8 needs additional study, because it is still unclear whether these lipid modulators act directly by binding to TRPM8 channels or indirectly by interacting with other proteins.

\section{References}

Andersson DA, Nash M, Bevan S (2007) Modulation of the cold-activated channel TRPM8 by lysophospholipids and polyunsaturated fatty acids. J Neurosci 27:3347-3355.

Babes A, Zorzon D, Reid G (2004) Two populations of cold-sensitive neurons in rat dorsal root ganglia and their modulation by nerve growth factor. Eur J Neurosci 20:2276-2282.

Clapham DE (2003) TRP channels as cellular sensors. Nature 426:517-524.

Peier AM, Moqrich A, Hergarden AC, Reeve AJ, Andersson DA, Story GM, Earley TJ, Dragoni I, McIntyre P, Bevan S, Patapoutian A (2002) A TRP channel that senses cold stimuli and menthol. Cell 108:705-715.

Vanden Abeele F, Zholos A, Bidaux G, Shuba Y, Thebault S, Beck B, Flourakis M, Panchin Y, Skryma R, Prevarskaya N (2006) Ca2+independent phospholipase A2-dependent gating of TRPM8 by lysophospholipids. J Biol Chem 281:40174-40182. 